\section{GASTRIC SYPHILIS."}

\author{
BY
}

DAVID J. GALLOWAY, M.D., F.R.C.P.EDIN.,

LECTURER ON THE PRACTIC OF MEDICINE, KING EDWARD VII SCHOOI OF MEDICINE, SINGAPORE.

Gastric syphilis was described twenty-five years ago by Lancereaux in his Traite de Syphilis, and references to it in Continental medical periodicals and textbooks are not in. frequent. In medical literature in the English language mention of such a condition has been rave, one very excellent textbook dismissing it in exactly seven words. Recently, however, reports of cases are becoming more frequent, especially from America, and we are driven to one of two con. clusions-either that this manifestation of syphilis is becoming more common, or that we are awaking to the fact of the existence of such a pathological entity. My belief is that, while by no means common, it is not the excessive rarity it is commonly assumed to be. There may be reasons for this belief: first, there is the ethnic one, my experience having been wholly among Asiatics; in them syphilis, especially untreated syphilis, is not only more common, but presents other pathological pictures than in Europeans; and, secondly, because my introduction to the disease was of such a nature as to leave in my mind no trace of doubt as to its existence, and to induce ar attitude of mind favourable to its discovery when present.

My first case occurred thirty years ago, when I was asked by the medical attendant of a patient to see him in consultation; a diagnosis of pyloric cancer had been made.

\section{CASE r.}

The patient was a Straits-boin Chinaman, 45 years of age, in easy circumstances. I had frequently met him, and recollected him as a well-built man inclined to stoutness although of active habits. When I saw him I had difficulty in recognizing him. He was emaciated to a degree, with dry wrinkled skin of that lemon tint which we associate with cachexia in Chinese. His features were sharpened, and he had the "facies" of serious illness. His complaint was all of his stomach. About five months previously he plaint was all of his stomach. About five months previously he of the stomach. If he forcel himself to eat bis discomfort was often so great that he had to excite vomiting to obtain relief. Soon the vomiting became spontaneous; lately he had vomited only once or twice in the twenty-four hours, bringing up a large quantity. He complained also greatly of thirst.

Fxamination in a good lisht showed a considerable bulging of the abdomen, and in its upper part waves of peristalsis were visible through the parchment-like abdominal walls, but in what visible through the parchment-like abdominal walls, but in what
direction these were travelling I have no note. By palpation and percussion a much dilated stomach was mapped out, the greater curvature being well below the umbilicus when in the horizontal position and sinking into the pelvis when he sat up. An attempt to elicit a "splash" was too much for the patient, and he was sick, bringing up a large quantity of greyish sour-smelling liquid. After he had rallied a little it was possible to make a much better exfinination, and a firm mass was felt lying mostly under though somewhat to the outer edge of the right rectus, about the level of the umbilicus. This mass had a co:ssiderable degree of movement. The liver and spleen were both palpable. I concurred in the diagnosis already made.

With a view to lessening his discomfort, the stomach was washed out and half a grain of calomel was given every hour for six hours, the idea being to lessen fermentation. He was allowed clear soups only, with sips of hot water, and the calomel was to be continued in doses of one-sixth of a grain every two hours. Ten days later I was asked to see him again, as such changes had taken place as to require a revision of our diagnosis. Since the washing out and dosage with calomel the vomiting had stopped; he seemed to digest what was given him, his appetite was coming back, and there was difficulty in keeping him on the diet prescribed. All this may occur in a case of pyloric cancar, as the result of local treatment at first, but the surprising factor in this case was that the tumour

was rapidly disappearing. On my second visit I found the patient a much altered man. "facies," there was no bulging in the abdomen, it was, in fact, scaphoid, and it was easy to feel a well-defined thickening, slightly higher and a little more to the right than the position previously occupied by the tumour. The liver and spleen were still enlarged; there was some mercurial stomatitis, but not excessive. To put it briefly, the antisyphilitic treatment was continued, the diet gradually increased, and in a little over four months he had regained his lost weight and was in robust health. He lived for twenty. five years after that, a life saved by a mere accident, and a standing reminder of our limitations. There was no history of syphidis obtainable.

Thíe patient I now show is peculiar in that he is the only European in my series. He came into my liands eighteen months ago, his case having been diagnosed by one medical

\footnotetext{
* Read vefore the Malaya Branch, British Medical Association.
}

man as cancer of the stomach, and by another as cancer of the head of the pancreas.

\section{CASE II.}

$\mathrm{He}$ is not very robust now but at the time of which I speak he was little more than a skeleton. A peaked swelling stood up in the centre of an area bounded above by the ensiform cartilage, below by the umbilicus, and laterally by the costal margins-an inch below the centre of the epigastrium: His hollow abdomen tended to exaggerate the prominence of the swelling, but viewed horizontally it stood higher than the level of the sternum. It moved with deep inspiration, could be freely palpated without pain, and it lacked the stony hardness which we associate with malignancy. He had been living on soups and milk for months. There was no dilatation of the stomach, no jaundice, and no spinai symptoms, but there was enlargement of both the liver and spleen, symptoms, but there was enlargement of both the liver and spleen,
which his emaciated state rendered easily palpable. He had $a$ history of syphilis, acquired in South Africa twelve years before and practically untreated, and stigmata of the disease were many. He was given $1 \mathrm{gr}$. doses of the yellow iodide of mercury three times daily until signs of saturation appeared, and then an intravenous injection of 0.6 gram novarsenobenzol. I left for Australia soon after, enjoining him to have a thorough treatment, but that is all he has had. The improvement worked by even such limited is all he has had. IT

There are other than tumour manifestations caused by syphilis, and the case I have cliosen to represent a second class is that of a Japanese woman from Taipeng.

\section{CASE III.}

Her history was that three months before she lost her appetite but could still digest soft foods. That ability was early lost and she began to vomit. Gradually a new symptom was added-pain, very much so by vomiting. From dread of vomiting, and on medical advice, her diet had been restricted to mill, and even that had latterly been returned. In the vomited matter she had lately noticed small clots of blood, and, if the effort had been severe, bright red blood was brought up towards the end of vomiting.

Signs of syphilis were many, and the only objective local sign was a thickening in the epigastrium, a little to the left of the middle line, very tender on manipulation, and there was enlargement of the liver. She was not pregnant. She was much ex hausted, and there was a strong acetone smell in the breath. The treatment had been very careful, and much resource had been shown in it.

For twenty-four hours she had nothing but full doses of sodium bicarbonate in hot water, most of which she retained, and then an intravenous injection of "914." The vomiting ceased at once, and after her dread of vomiting had gone she began to take food in quantity. After a course of combined mercury and "914" she returned home cured.

As typical of a third, and by far the most numerous, class of case I have taken that of a Chinese merchant, 53 years of age, a man much above the average both physically and mentally.

\section{CASE IV.}

He had contracte 1 syphilis twenty-two years previously, for which he had had no treatment. I had seen him frequentil, his usual complaint being a sore mouth, caused by mucous patches irritated by excessive cigar smoking. A few weeks on iodide and mercury perchloride and the application to the patches of chromic acid paint cleared this up, and he stopped treatment as soon as comfort was attained. On this occasion, however, it was not the tongue, all his complaint was of his stomach. For over a month he had been losing all desire for food and had trouble in digesting what little he took. His troubles were worst at night so that he had been taking no food after 2 p.m., but even then he had sometimes to induce vomiting before he could sleep, and the vomit was the food he had taken early in the day, little changed.

Examination of the abdomen was not satisfactory as he was rather stout with a thick abdominal wall, but enlargement of both liver and spleen could be made out. Deep pressure in the epi gastrium elicited only slight tenderness. The tongue was remarkably clean though still showing thin mucous patches, and the mouth was, generally, in good condition. The urine was free from albumin and sugar, but there was a pronounced indican reaction. He was treated for dyspepsia and both medicines and diet frequently changed because of the entire lack of success with any.

After three weeks of this he was decidedly worse, had lost much weight, and had developed a slight temperature. Anorexia was absolute, but his thirst was great. A trace of sugar was found in the urine and malarial parasites were found in the blood, probably accounting for the temperature. A better examination of the abdomen could now be made, but it resulted in nothing more than the previous one, but the skin had assumed the dry inelastic feel and lemon tint of cachexia. It was while making this examination that it flashed into my mind that I was dealing with a case of syphilis of the stomich, and acting on this, I dis carded all other treatment and gave an intravenous injection of novarsenobenzol. The result was almost theatrical, and in a day or two he was able to eat with relish. A course of treatment soon restored him to his normal condition, minus the sore tongue.

You will probably agiee with the statement that in its power of mimesis of other diseases syphilis runs hysteria a close second, for however much my description of the cases 
may have fallen short, I can assure you that clinically they were very presentable pictures of three distinct gastric con. ditions-malignant tumour, gastric ulcer, and a subacute gastritis. I was fortunate in getting histories of infection in the majority of my cases-I say fortunate, as you all lnow the difficulty of obtaining a medical history of any kind from a native, to whom the acquisition of a venereal disease is a mere incident. From the histories and from a consideration of all the collateral circumstances in those from whom no history could be obtained, I was led to the conclusion that all of them were the result of the acquired disease. The youngest, and also the earliest after the date of infection, was a female, 28 years of ago, with a clear history of infection six years previously.

The comparative rarity of the definite tumour formation may be judged when I say that in thirty-five years I have encountered it only seven times; all were males, and only one European. In three the symptoms of obstruction with dilatation of the stomach were very definite; in one, the European, there were signs of a partial obstruction, and in the remaining three there were no signs of obstruction whatever. In the European the swelling lay in the middle line, and yet it produced some obstruction as only fluids could pass. This can be explained only on the hypothesis that, by its size, it caused a distortion of the gastric planes and thus obstruction. In the other non-dilated cases the site of the tumour was to the right of the middle line, so that, of the seven cases, six were in the pyloric region.

I am unable to add anything to our knowledge of the pathology of these conditions as I have had no fatal case, but writers on this subject are fairly well agreed as to the changes to be found. These are two-syphilitic endarteritis and gummatous formations. Of the latter three forms are described-small discrete gummata scattered all over the mucous membrane, flat diffuse gummata, and gummatous tumour. I do not think there is much room for doubt that these tumour cases were of the latter variety. Although I have had no death $I$ believe myself justified in stating that the course of these cases would differ little from that of the most acute type of malignant disease. In none, excepting the European, did the history of gastric trouble extend beyond six months. The condition of the dilated cases was grave enough to warrant a belief that they were within measurable distance of their end, and, what with the absolute anorexia, the abeyance of gastric function and the cachexia, I do not think that the course of the non-dilated cases would have been much longer than the dilated. The European dated the beginning of his symptoms back twelve months. Early diagnosis is therefore a desideratum, and to that end it would be a prudent measure, having diagnosed an organic lesion of the stomach, either to confirm or eliminate syphilis by a Wassermann or Noguchi test.

The only symptom which might give a pointer is the natare of the pain. While there do occur cases of malignant disease of the stomach which throughout their course are "silent," they are the exception. Pain in malignant disease is usually a prominent symptom, occurring erratically, radiating widely, always severe, often indeed agonizing, disappearing completely for a time. Pain in gastric syphilis is never at any time pronounced, but it is always there, dull and constant, sometimes better, sometimes worse, especially at night, and limited to a zone extending right round the body a little below the level of the diaphragm. There is of course always the possibility of such cases merging into malignancy, as o!d syphilitic lesions do in other parts of the body, and it would not surprise me if the case shown to-night should, in its half-treated condition, follow that course.

The second group of cases, those mimetic of gastric ulcer, are not as a rule difficult of diagnosis. Though vomiting is a symptom, the excessive vomiting in the illustrative case is unusual, and unless of spinal origin not easily explained. The symptoms common to all were thickening, sometimes almost amounting to tumour formation, in the epigastrium, tenderness on palpation, vomiting, and the presence of blood in the vomited matter. Taling the three cardinal symptoms of gastric ulcer, pain, vomiting, and haemorrhage, and discussing them seriatim, it is possible to go some distance towards establishing a diagnosis. Pain in gastric ulcer is brought on, or much aggravated by, eating, and is relieved to a corresponding extent by vomiting. It is usually located in one spot, a "point of pain," is intense, and there is generally a point of referred pain, usually in the back. In ulcerated gumma of the stomach, which $I$ take to be the pathological condition, there is a constant substratum of pain, not much aggravated by eating, but greatly so by the effort of vomiting, radiating laterally, and forming a girdle of pain which, as usual, is worse at night. Vomiting is common to both conditions.

Haemorrhage in gastric ulcer is usually copious, coffee. ground, or bright red, according to its time of retention. In gummatous ulcer the blood comes up only with food, is in small clots, and bright red only at the end of a severe effort of vomiting. There is a possibility of a true peptic ulcer developing in a stomach which is the site of syphilitic endarteritis.

The third class-those resembling subacute gastric catarrh -are more common than is generally assumed, at least among Asiatics, and they range from those having only subjective symptoms to thcse in whom the local condition verges on tumour formation.

Somo assistance in diagnosis may be had from test meals, as all the cases in which it was given had a pronounced hypochlorhydria. They are too few to generalize upon, but it is significant that the condition was the same in all.

To summarize briefly, there are two symptoms and three signs. The symptoms are, first, anorexia-I know of no condition in which it is so absolute, excepting in some early cases of malignant disease-and second, the nature of the pain. The signs are, first, enlargement of the liver (and occasionally also of the spleen), with smooth outline, present in three-fourths of all cases; secondly, rapid development of cachexia ; and thirdly, stigmata of syphilis.

The real test is the empiric, the therapeutic, and that may be applied both from its negative and positive aspects. It seems to be immaterial what care is expended or with what ingenuity drugs and diets are tried and changed, the result is nil. On the other hand, when specific treatment is begun, the change is immediate, often dramatic. In the presalvarsan days, from which period the most of my cases are taken, the prescription of choice was calomel $\frac{1}{2}$ grain, with sodium bicarbonate 10 grains, and heavy magnesium carbonate 10 grains, given thrice daily with hot water on an empty stomach, and continued until signs of mercurial saturation appeared. After the first day or two, as soon as mercury began to be absorbed, improvement began and was generally very rapid. There was always the possibility that local action shared in bringing about the improvement, but now that is eliminated and negatived, as intravenous injec. tion of novarsenobenzol acts on the stomach condition immediately.

\section{SOME PRINCIPLES OF AFTER-TREATMENT IN ACU'IE ABDOMINAL DISEASE.}

BY

H. W. L. MOLESWORTH, F.R.C.S. ENG.,

FOLKESTONE; LATE SURGICAL REGISTRAR, LONDON HOSPITAL.

This paper is founded on the results of trying the more modern methods of after-treatment in a series of just under 300 cases of acute abdominal disorders, on which I have operated in the last two years. During the same period I had the opportunity of observing many cases operated on by others, and, since they were seen, it is impossible to avoid taking them into consideration.

An attempt has been made to follow the results of post-mortem examinations and the appearances observed at second operations, and to bring these findings to bear on technique and on after-treatment.

In surgery some older methods are being abandoned for those we believe to be better; but in nearly all conditions it is being increasingly recognized that the operation is but a part of the treatment. It is also becoming manifest that, apart from the particular manipulation called the operation, the great therapeutic agent is rest. It is astounding to realize how little we have advanced in basic principles of treatment since the time of Hilton. With all our elaboration of technique, the almost universal objective of surgery is to provide the patient with an easier task in overcoming the damaging agent.

At the conclusion of an emergency laparotomy the patient is left with a double task. He has to repair the ravagat of his disease, and to overcome those portions of the damaging agent which the surgeon has left behind. He has also to repair the injuries inflicted by the surgeon, who, unlike the

* Paper read before the Kent Branch, British Medical Association, at Bromles, December 8th, 1921. 